\title{
ON APANTHURETTA LATHRIDIA N. SP. (CRUSTACEA, ISOPODA, ANTHURIDEA) FROM CUBA
}

\author{
by \\ JOHANN WOLFGANG WÄGELE \\ Fachbereich Biologie, Universität Oldenburg, P.O.B. 2503, D-2900 Oldenburg, F. R. G.
}

\section{ABSTRACT}

Apantburetza lathridia n. sp. (Crustacea: Isopoda: Anthuridea), the fifth species of the genus Apantburetta Wägele, is described from interstitial water of a Cuban beach. $\mathbf{A}$ high number of morphological similarities with Apanthuretta pori Wägele (Red Sea) is noted.

\section{ZUSAMMENFASSUNG}

Apanthuretta latbridia sp. n. (Crustacea: Isopoda: Anthuridea), die fünfte Art der Gattung Apantburetta Wägele, wird aus interstitiellem Wasser eines kubanischen Strandes beschrieben. Eine hohe Zahl von morphologischen Ubereinstim. mungen mit Apanthuretta pori Wägele (Rotes Meer) konnte festgestellt werden.

\section{INTRODUCTION}

An astonishing number of Crustacea has been discovered in the hypogean waters of the Caribbean area, among them various isopods. Isopoda Anthuridea are known from this area mostly from limnic and cave habitats (Cyatbura curassavica Stork, 1940; C. specus Bowman, 1965) but also from the interstitial water of beaches (Curassanthura Kensley, 1981). The present species was discovered in the interstitial water of a Cuban beach and it is the first species of the genus Apanthuretta Wägele to be found in such a habitat: up to now only three marine Caribbean species of this genus and one species from the Red Sea were known (Wägele, in press).

\section{LIST OF ABBREVIATIONS}

\begin{tabular}{|c|c|c|c|}
\hline A 1 & antenn.: 1 & P 1.7 & pereopods 1.7 \\
\hline A 2 & antenna 2 & Plp 1-5 & pleopods 1.5 \\
\hline $\mathrm{Hy}$ & hypopharynx & Tel & telson \\
\hline $\mathrm{Md}$ & mandible & UEx & exopod of uropod \\
\hline $\mathrm{Mx}$ & maxilla 1 & UEn & endopod of uropod \\
\hline Mxp & maxilliped & ZMA & $\begin{array}{l}\text { Zoölogisch Museum } \\
\text { Amsterdam }\end{array}$ \\
\hline
\end{tabular}

\section{SYSTEMATICS}

Holotype: non-reproductive adult, $2.7 \mathrm{~mm}$, ZMA. Locus typicus: Cuba, Playa Siboney not far from Santiago de Cuba, on the shores of the Caribbean Sea, in interstitial water (temperature: $28^{\circ} \mathrm{C}$ ) of a beach of coarse sand. Holes were dug in the sand, just above the water line, and interstitial water filling the holes was filtered through a net, enabling the collection of a very rich interstitial fauna (leg. L. Botosaneanu, 15.II.1973).

Description of the holotype. Cephalothorax quadratic in dorsal view; small lateral eyes present. Relative length of pereonites: $1 \geq 2>3<4=5>6>7$. Pleon somewhat longer than pereonite 7 (fig. 1 ), pleonites $4+5$ fused dorsally, the other sutures visible in dorsal view. Dorsal surface of pleon and pereon bearing no chromatophores. Flagellum of A 1 (fig. 2) 3segmented; first article short, with 1 feather-like bristle, second article longer, third article small, with 3 aesthetascs and several (8) setae. Flagellum of A 2 short, with 3 articles bearing many short setae. Md with 3-segmented palp, last article short, with 3 setae. Pars incisiva with three notches, lamina dentata indistinctly serrated, pars molaris prominent. Lateral endite of $\mathrm{Mx}$ with 7 distal spine-like teeth, medial endite short, with 1 seta. Hy see fig. 2. Mxp (fig. 1) 4-segmented; last article fused with the third (fusion line visible), bearing 5 distal setae. P 1 (fig. 2) subchelate, propodus with a blade-like palm that ends distally with an angular projection, palm bearing 4 setae; medial side of propodus with 4 setae; claw longer than dactylus. P 2 and P 3 not subchelate, propodus long oval, palm bearing a medial stout seta and a distal sensory spine, medial side with 3 setae 


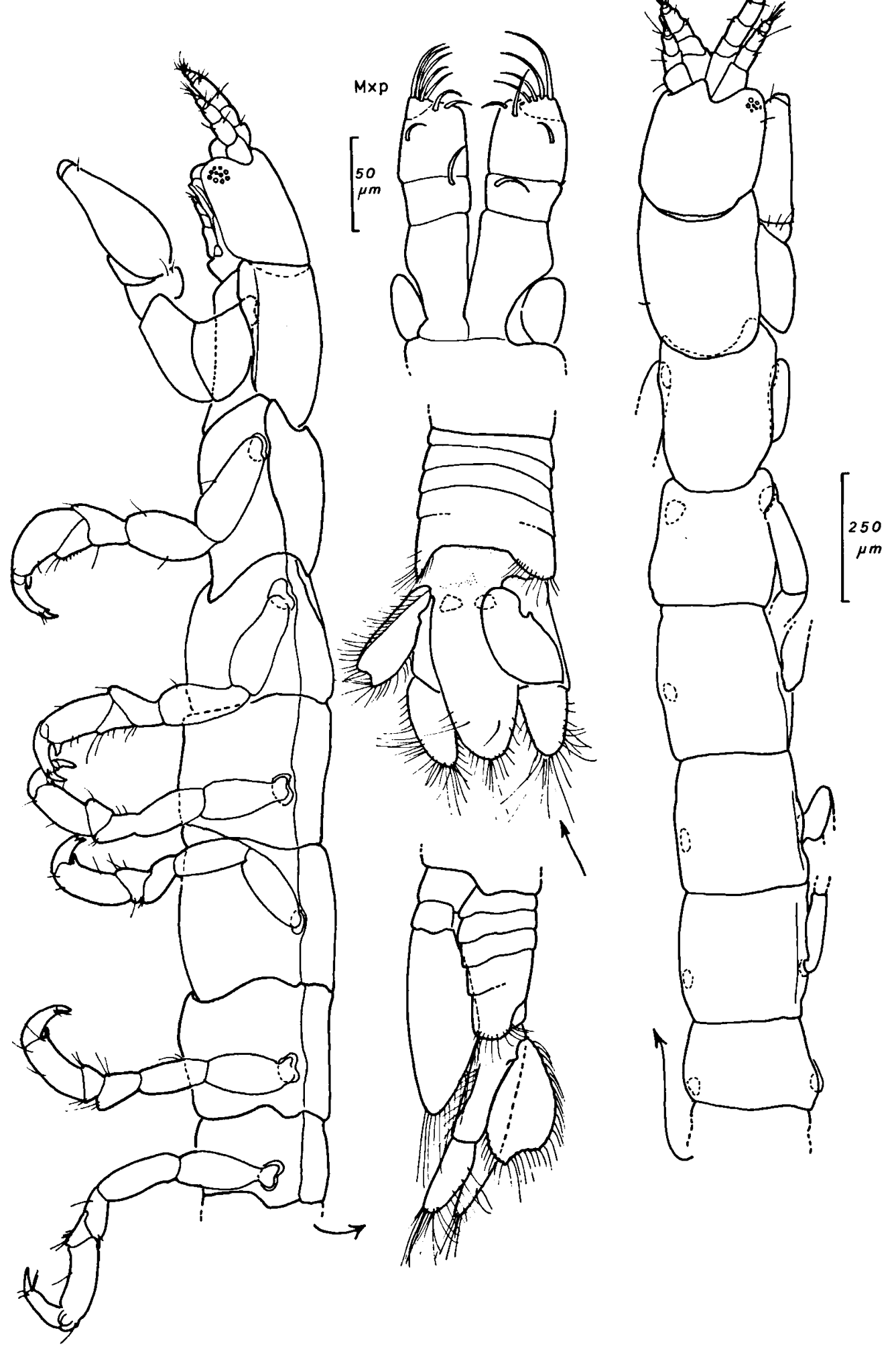

Fig. 1. Apanthuretta lathridia n. sp., non-reproductive adult, holotype, in dorsal and lateral view. 
BIJDRAGEN TOT DE DIERKUNDE, 52 (1) 1982

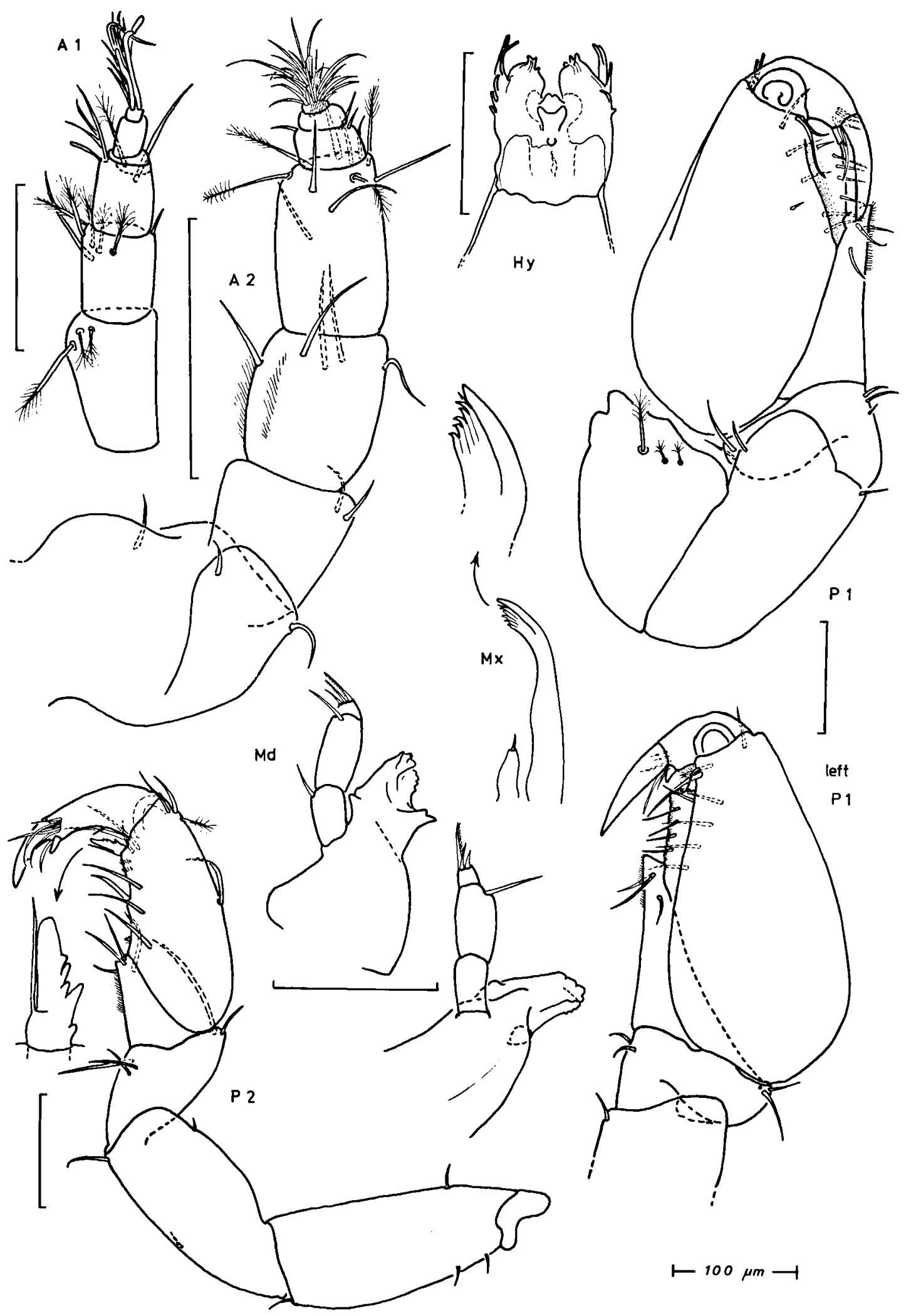

Fig. 2. Apanthuretta latbridia n. sp., holotype. 


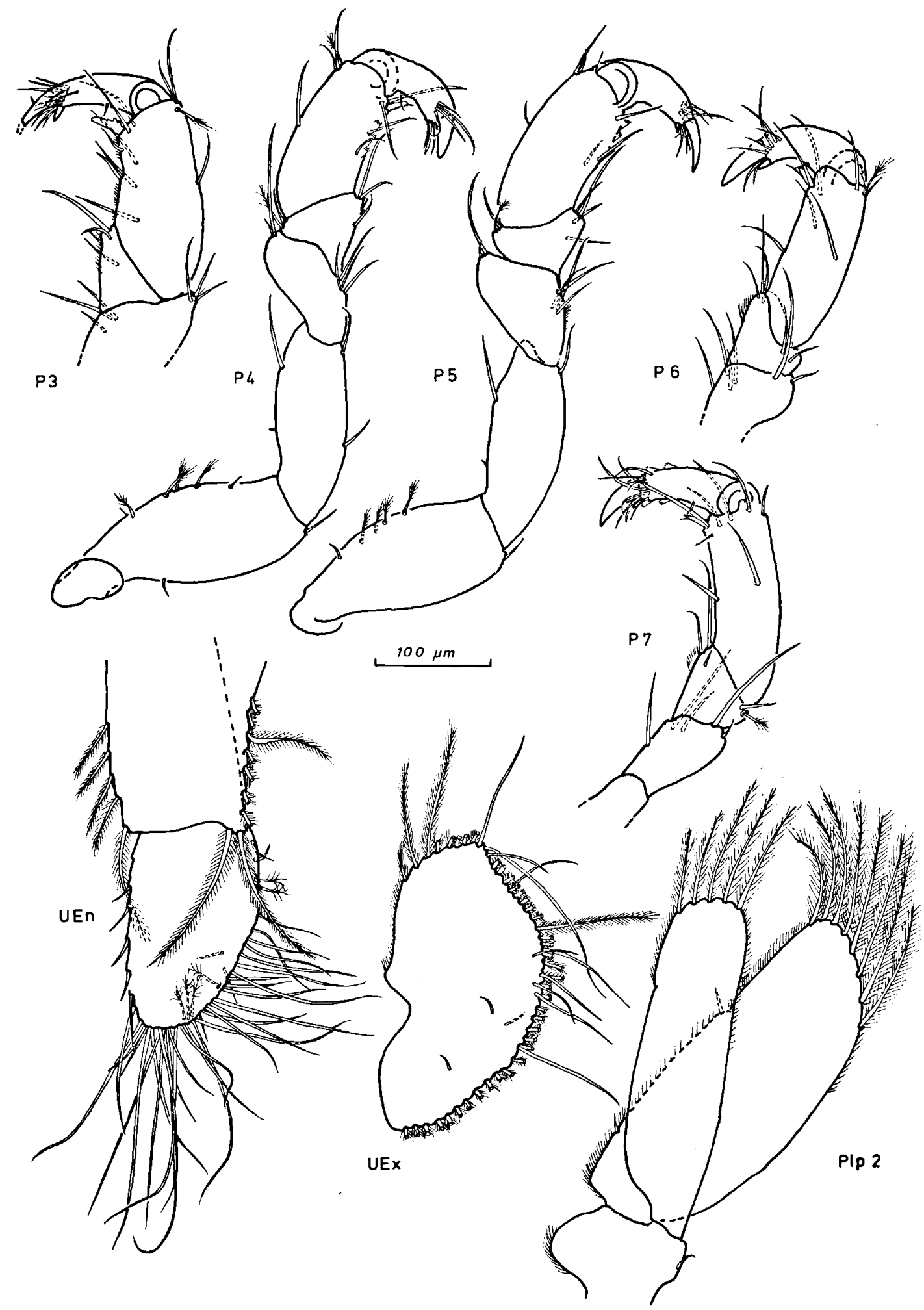

Fig. 3. Apanthuretta lathridia n. sp., holotype. Some plumose setae of UEn and UEx cut off. 
(figs. 2, 3). Carpus of P 4-P 7 short, trapezoidal, propodus long oval, setation see fig. 3. Plp 1 operculiform, exopod with 29, endopod with 6 swimming setae (fig. 4). Exopod of Plp 2 with 8, endopod with 5 swimming setae (fig. 3 ). Uropods not surpassing telson, UEx (fig. 3) oval with slight distal concavity on outer margin, UEn shorter than sympod, longly oval, setation see fig. 3. Telson dorsally slightly convex, with 2 statocysts, distal margin with 4 pairs of setae (fig. 4).

\section{REMARKS}

Many descriptions of species of isopods are incomplete, "like badly preserved fossils" *: Science only knows the structure of some parts of the animals, the parts varying from author to author. The taxonomist then has severe difficulties in finding the generic features in such a group of

* Expression due to Prof. H. K. Schminke, Oldenburg. species, a task that per se is not easy. Such a "difficult" genus is Apanthura Stebbing, 1900. The genus Apanthuretta Wägele (in press) is very similar to Apantbura in the form and setation of antennae, maxillipeds, pereopods and telson. Apanthuretta is distinguished by the fusion of pleonites $4+5$ (suture line not visible) and the lacking endite of the Mxp. Other and better generic features are not known, as most of the descriptions are incomplete. In this situation the discovery of another species with the same generic features supports the supposition, that these species must have an own history in comparison with the Apanthura-group.

Comparing Apantburetta latbridia n. sp. with the type species $A$. pori Wägele (in press) a conformity in setation is found. The blind $A$. pori has longer antennae. The $\mathrm{Mxp}$ are nearly identical, the fusion line between the articles 3 and 4 is less distinct in $A$. latbridia n. sp. The mandibular palp of $A$. pori has only 2 setae. Both species have 3 aesthetasc-like growths on the lateral lobes of

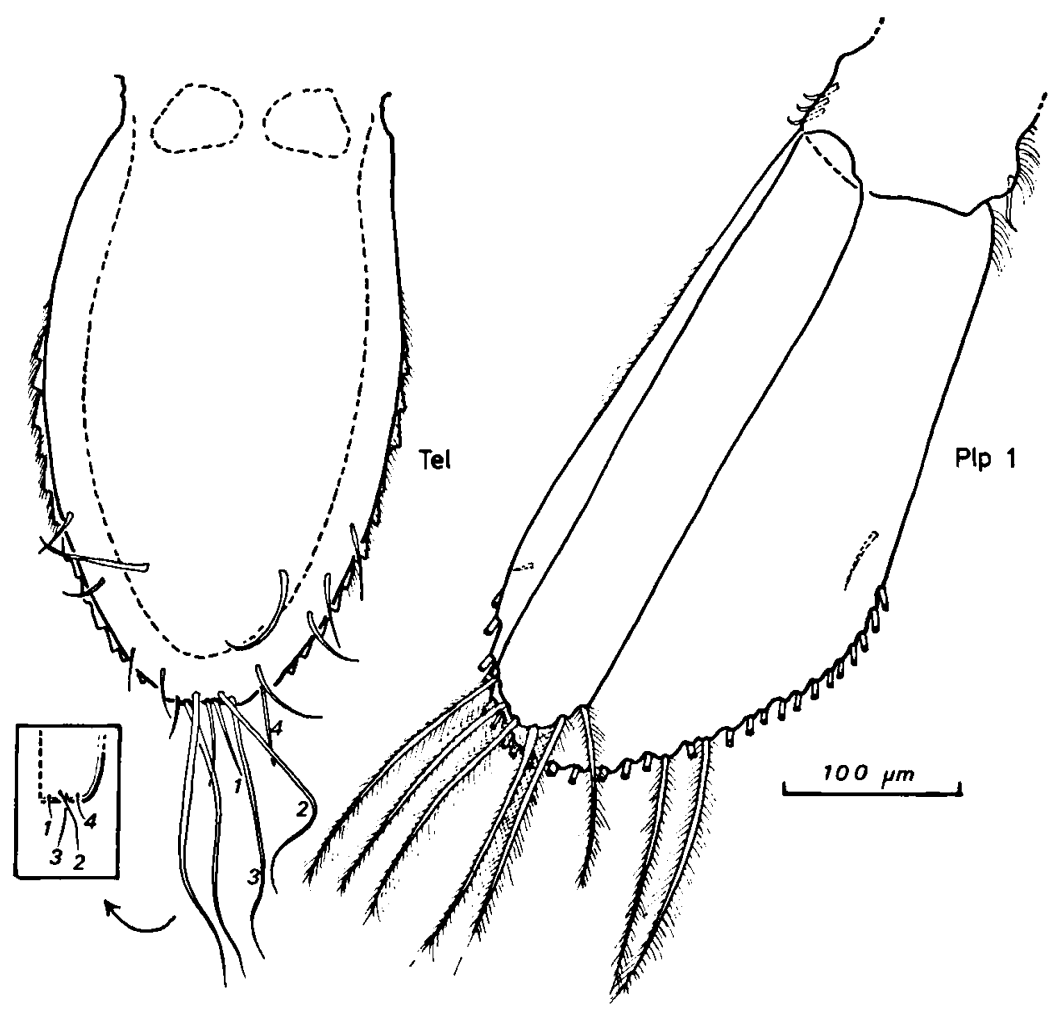

Fig. 4. Apanthuretta lathridia n. sp., holotype. Some swimming setae of Plp 1 cut off. 
the $\mathrm{Hy}$, the palm of $\mathrm{P} \mathbf{1}$ has the same contour in the non-reproductive adult. The juvenile of $A$. pori has no distal projection on the palm. $A$. pori has no medial stout seta on the palm of $\mathrm{P} 2$ and $\mathrm{P}$ 3. Though being less than half as long as $A$. pori, $A$. latbridia n. sp. has nearly the same number of setae on the pleopods. The telson of $A$. pori has only 3 distal pairs of setae.

The other species of Apantburetta are difficult to compare. All of them have eyes; $A$. signata (Menzies \& Glynn, 1968) has dorsal chromatophores. The projection on the palm of $\mathrm{P} 1$ of A. magnifica (Menzies \& Frankenberg, 1966) is situated more proximally, males have an acute tooth (Menzies \& Frankenberg, 1966; Kensley, 1980). The descriptions of the setation of the Mxp are variable, but the third article always has an additional medial seta. Kensley (1980) found on a SEM picture an endite of the Mxp, but no direct connection of the endite with the basipodite is visible (the endite resembles very much the medial endite of the $\mathrm{Mx}$, which is connected with the Mxp by the medioventral sclerite (Scheloske, 1977)); it remains uncertain whether some species of Apantburetta still have an endite of the Mxp. The $\mathrm{P} 2$ of $A$. magnifica has more setae (Schultz, 1979) than in $A$. latbridia n. sp. The telson of $A$. magnifica seems to bear many long setae (Kruczynski \& Myers, 1976; Schultz, 1979). A. significa (Paul \& Menzies, 1971) has no marked projection on the palm of $\mathrm{P} 1$, the palp of the Md has 2 long setae on the second article. The $\mathbf{P} 1$ of $A$. signata (Menzies \& Glynn, 1968) is similar to that of $A$. latbridia n. sp., the Mxp has more setae.

\section{ACKNOWLEDGEMENT}

My sincere thanks are due to Dr. L. Botosaneanu for the loan of the specimen he collected in Cuba.

\section{REFERENCES}

Bowman, T. E., 1965. Cyathura specus, a new cave isopod from Cuba (Anthuroidea: Anthuridae). Stud. Fauna Curaçao, 22 (85): 87-97.

Kensley, B., 1980. Records of anthurids from Florida, Central America, and South America (Crustacea: Isopoda: Anthuridea). Proc. biol. Soc. Wash., 93: 725-742.

- 1981. Amsterdam Expeditions to the West Indian Islands, Report 10. Curassanthura halma, a new genus and species of interstitial isopod from Curaçao, West Indies (Crustacea: Isopoda: Paranthuridae). Bijdr. Dierk., 51 (1): 131-134.

KRUCZYNSKI, W. L. \& G. J. MYERS, 1976. Occurrence of Apanthura magnifica Menzies \& Frankenberg, 1966 from the west coast of Florida, with a key to the species of Apanthura Stebbing, 1900. Proc. biol. Soc. Wash., 89: 353-360.

Menzies, R. J. \& D. Frankenberg, 1966. Handbook on the common marine isopod Crustacea of Georgia: 1-93 (Univ. Georgia Press, Athens).

Menzies, R. J. \& P. W. GlynN, 1968. The common marine isopod Crustacea of Puerto Rico. Stud. Fauna Curaçao, 27 (104): 1-133.

Paul, A. Z. \& R. J. Menzies, 1971. Sub-tidal isopods of the Fosa de Cariaco, Venezuela, with descriptions of two new genera and twelve new species. Boln. Inst. oceanogr., Cumana, 10 (1): 29-48.

SCheloske, H. W., 1977. Skelett und Muskulatur des Cephalothorax von Asellus aquaticus (L.) (Asellidae, Isopoda). Zool. Jb. (Anat.), 97: 157-293.

Schultz, G. A., 1979. A new Asellota (Stenetriidae) and two, one new, Anthuridea (Anthuridae) from Bermuda (Crustacea, Isopoda). Proc. biol. Soc. Wash., 91: 904-911.

Stork, H. A., 1940. A new fresh-water isopod from Curaçao. Stud. Fauna Curaçao, 2 (10): 147-150.

WÄgele, J. W., in press. Study of the Anthuridea (Crustacea, Isopoda) from the Mediterranean and the Red Sea. The family Anthuridae. Isr. J. Zool. 